\title{
Competentiegerichte selectie van toekomstige urologen: ervaringen uit de praktijk
}

\author{
R.P.J.M. van de Loo
}

\section{Samenvatting}

Een duidelijke structuur, een competentiegerichte benadering op basis van een competentieprofiel en een heldere verankering van verantwoordelijkheden wat betreft de organisatie, uitvoering en kwaliteitsbewaking zijn de bouwstenen van de selectieprocedure voor Nederlandse assistenten in opleiding tot uroloog. De procedure kent drie fasen: een schriftelijke voorselectie, een interviewsessie door een panel van urologen en een sollicitatieronde in de opleidingsclusters. Zowel de gekozen opzet als het opgestelde competentieprofiel worden kritisch besproken in het licht van drie essentiële criteria bij het inrichten van een selectieprocedure: zorgvuldigheid, transparantie en validiteit. Gewezen wordt op het belang om een procedure kritisch te blijven monitoren en onderzoek te doen naar de validiteit van procedure en competentieprofiel. Ook mogelijke implicaties van de huidige discussie over eindtermen en algemene competenties voor medisch specialisten komen aan de orde. (Loo RPJM van de. Competentiegerichte selectie van toekomstige urologen: ervaringen uit de praktijk. Tijdschrift voor Medisch Onderwijs 2004;23(1):30-39.)

\section{Inleiding}

In sollicitatieprocedures gebeuren soms zaken die geen schoonheidsprijs verdienen: onvoldoende voorbereiding door de selectiecommissie op het selectiegesprek, geen duidelijk en gemeenschappelijk beeld van de functie- en/of opleidingseisen bij de leden van deze commissie, een procedure waarbij van te voren al min of meer vast staat welke kandidaat wordt geselecteerd, onzorgvuldig omgaan met sollicitatiebrieven en andere vertrouwelijke gegevens, waardoor stukken kwijtraken of vertrouwelijke informatie openbaar wordt. Het is niet zonder reden dat de beroepsvereniging van $\mathrm{P} \& \mathrm{O}$-adviseurs in Nederland een sollicitatiecode heeft opgesteld met een aantal basisregels voor het vervullen van vacatures in arbeidsorganisaties. ${ }^{1}$ Om dezelfde reden hanteert de Nederlandse Vereniging voor Urologie (NVU) drie centrale uitgangspunten in haar selectieprocedure voor assistenten in opleiding: zorgvuldigheid, transparantie en validiteit. ${ }^{2}$ Dit artikel schetst hoe deze selectieprocedure is opgezet met als leidraad deze drie uitgangspunten.

\section{Organisatie van de selectieprocedure}

Er is gekozen voor één jaarlijkse selectieprocedure, waarbij de coördinatie en praktische organisatie geconcentreerd zijn op één centraal punt: het secretariaat van de Nederlandse Vereniging voor Urologie. Hier melden kandidaten zich aan, hier worden alle relevante gegevens vastgelegd en vanuit dit punt wordt alle informatie over de procedure gedistribueerd, in toenemende mate ook via de website. Kandidaten weten daardoor waaraan ze toe zijn, waar informatie beschikbaar is en de NVU houdt op deze manier het overzicht over de procedure en het verloop ervan, zodat tijdig bijgestuurd kan worden.

Verantwoordelijk voor de opzet en structuur van de procedure is de Toela- 
tingscommissie Urologie (TCU), waarin opleiders urologie, zowel uit de academische setting als uit de periferie, zitting hebben. De TCU legt op haar beurt verantwoording af aan de NVU. Dit gebeurt onder meer door jaarlijks verslag te doen van het verloop en de resultaten van de selectieprocedure in een intern rapport en in een publikatie in De Urograaf.

\section{Selectie in drie fasen}

De selectieprocedure heeft een gefaseerde structuur. Figuur 1 geeft het overzicht van de procedure in vogelvlucht.

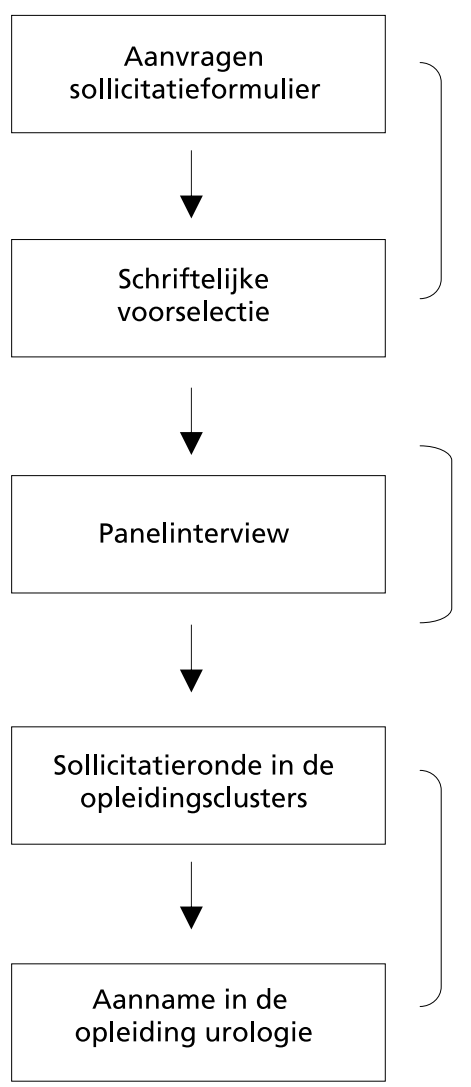

Fase 1

Fase 2

Fase 3

Figuur 1. De selectieprocedure in vogelvlucht.

\section{Fase 1: schriftelijke aanmelding en voorselectie}

In de eerste fase beoordeelt de Toelatingscommissie Urologie alle ingekomen sollicitatieformulieren op formele criteria, zoals de eis dat men het artsexamen heeft behaald. Daarnaast wordt elke kandidaat beoordeeld op zes competenties die in deze specialisatie van belang zijn. Deze zes aspecten zijn: vakgerichtheid, werken in teamverband, integer handelen, oordeelsvorming, praktische vaardigheid en plannen en organiseren. Over deze kwaliteiten bevat het sollicitatieformulier gerichte vragen, waardoor dit formulier een gestructureerde opzet heeft. De beoordeling gebeurt op basis van de antwoorden van de kandidaat alsmede op basis van bijgevoegde bijlagen, zoals referenties, cijferlijsten en diploma's. De beoordeling richt zich vooral op aantoonbare ervaring en interesse in dit specialisme, zoals assistentschappen, publicaties en onderzoeksparticipatie. Uit onderzoek, in elk geval bij internisten, blijkt dat de hoogte van de cijfers voor het co-schap in dat specialisme de beste voorspeller is voor later succes in dit specialisme. ${ }^{3}$ Daarentegen blijken algemene studiecijfers later beroepssucces nauwelijks adequaat te voorspellen. ${ }^{4}$ Drie beoordelaars (twee leden van de TCU en een externe adviseur - een psycholoog) beoordelen elke kandidaat onafhankelijk van elkaar zowel op de zes competenties als op algemene geschiktheid voor de urologie. Daarna worden de gegeven oordelen besproken. De selectie richt zich in deze fase op het tegenhouden van duidelijk niet-geschikten voor dit specialisme. De laatste jaren zijn in deze fase steeds van de 30 tot 35 sollicitanten ongeveer drie kandidaten afgewezen. De drie beoordelaars blijken doorgaans een grote mate van overeenstemming in hun oordeel te hebben. 


\section{Fase 2: interview door een panel van deskundigen}

Kandidaten die door de schriftelijke voorselectie komen mogen zich vervolgens presenteren voor een panel van urologen. Voor deze panelgesprekken is één dag gereserveerd. Om zo veel mogelijk kandidaten de gelegenheid te geven zich persoonlijk te presenteren, zijn er vier panels, elk bestaande uit vier tot vijf ervaren urologen. Elk panel ziet 8 kandidaten; voor elk gesprek is 40 minuten uitgetrokken. De vier panels hanteren de methodiek van het zogeheten gestructureerde interview. Uit onderzoek is gebleken dat de voorspellende waarde (de predictieve validiteit) van het gestructureerde interview significant groter is dan het zogeheten vrije interview. ${ }^{5}$ Kenmerken van de hier gehanteerde structuur zijn:

- Bij elke kandidaat zijn meer interviewers en beoordelaars betrokken.

- Er is een duidelijke rol- en taakverdeling binnen elk panel: de voorzitter ontvangt de kandidaat, leidt het gesprek in en heeft de algehele regie in handen; twee panelleden interviewen om beurten, waarbij de onderwerpen zijn verdeeld.

- Er is een duidelijke scheiding tussen de fase van informatieverzameling (tijdens het interview) en het beoordelingsproces (na het interview).

- Elk panellid beoordeelt een kandidaat eerst op individuele basis; pas daarna vindt discussie en verdere oordeelsvorming plaats.

- De beoordelingen worden mede uitgedrukt in een score op een beoordelingsschaal.

- Zowel het interview als de beoordelingen zijn gericht op dezelfde set van kwaliteiten (competenties) als die waarover een toekomstig uroloog dient te beschikken.
De gevolgde werkwijze vergroot aanzienlijk de vergelijkbaarheid van de interviewresultaten, niet alleen binnen één panel maar ook tussen de vier panels onderling. Uit de jaarlijks verkregen evaluaties van kandidaten blijkt dat zij in deze aanpak de duidelijkheid en zorgvuldigheid waarderen. Door enkelen wordt als bezwaar genoemd dat er maar één keer per jaar gelegenheid is te solliciteren. Aan het einde van de paneldag worden alle kandidaten in een plenaire sessie van de vier panels besproken en wordt op basis van de gegeven oordelen definitief bepaald welke kandidaten mogen doorstromen naar de laatste fase van de selectie. Niet-geselecteerde kandidaten krijgen de kans het volgend jaar nog éénmaal deel te nemen aan de selectieprocedure.

\section{Fase 3: sollicitatieronde in de opleidings- clusters}

In de laatste fase in de selectieprocedure mogen die kandidaten, die een positief oordeel hebben gekregen, solliciteren in de zes opleidingsclusters urologie. In deze fase geldt het 'open markt'-principe. Kandidaten zijn vrij te kiezen, evenals de opleiders.

\section{Competentiegerichte benadering in de selectie}

Sinds enkele jaren vormen competenties de ruggegraat van de selectieprocedure. Competenties zijn eerder in dit tijdschrift omschreven als beroepsbekwaamheden, die nodig zijn voor het uitvoeren van beroepswerkzaamheden en die worden gekenmerkt door een samenhang van kennis en vaardigheden. ${ }^{6}$ Daarnaast hangen beroepsbekwaamheden en dus ook competenties samen met motivatie en persoonlijkheid. Dit maakt een competentie tot een complex en daardoor ook lastig te operationaliseren begrip. Het gaat bij 
competenties om relatief brede, beroepsgerichte categorieën die aangeven wat iemand in huis moet hebben om succesvol in het werk te zijn. Hoekstra en Van Sluis (1998) leggen in hun definitie de nadruk op de objectieve waarneembaarheid van effectief gedrag in een functie. Zij hanteren de volgende definitie: "Een latent vermogen van de persoon tot effectief presteren in een bepaalde taak- of probleemsituatie op een wijze die objectief waarneembaar en te beoordelen is." 7 Competenties als uitgangspunt voor selectie en opleiding zijn in korte tijd zeer populair geworden. Ook in de medische wereld rukt de competentiebenadering op. ${ }^{8}$ Die populariteit hangt samen met de volgende aspecten:

- Competenties bieden door hun uitgebreide omschrijving een gemeenschappelijke taal en daardoor een gemeenschappelijk kader voor een selectieprocedure.

- Competenties brengen brede, persoonsgerichte aspecten in kaart, wat een duurzamer karakter heeft dan relatief snel achterhaalde functie-eisen.

- Competenties maken de vertaalslag naar de specifieke beroeps- of opleidingscontext en zijn gedefinieerd in termen van concreet observeerbaar gedrag.

\section{Het competentieprofiel 'Toekomstig Uroloog'}

In deze selectieprocedure vormt het competentieprofiel 'Toekomstig Uroloog' leidraad en uitgangspunt. ${ }^{9}$ Dit profiel is opgesteld door vertegenwoordigers van het beroepsveld zelf, in dit geval door de leden van de toelatingscommissie. In een aantal werkconferenties onder begeleiding van een extern bureau heeft deze commissie gereflecteerd op wat een basisarts tot een waardevolle en capabele assistent in opleiding maakt. Bij de selectie van competen- ties is gebruik gemaakt van een algemene lijst van 36 competenties ${ }^{10}$ en van beschikbare documentatie, zoals relevante literatuur en in de loop der jaren verzamelde evaluatiegegevens over assistenten in opleiding tot uroloog. Bij de selectie van relevante competenties is expliciet rekening gehouden met actuele en toekomstige ontwikkelingen in de beroepspraktijk van de uroloog, zoals de grotere nadruk op samenwerking met andere medische disciplines, de toename in poliklinisch werk, het afnemend snijdend karakter door de toename van endoscopische en andere technologieën, de toenemende rol van informatisering en automatisering en door het mondiger worden van de patiënt.

Het competentieprofiel 'Toekomstig Uroloog' omvat de volgende competenties:

- Vakgerichtheid.

- Werken in teamverband.

- Integer handelen.

- Oordeelsvorming.

- Praktische vaardigheid.

- Plannen en organiseren.

- Interpersoonlijke sensitiviteit.

- Aandacht voor kwaliteit.

- Zelfvertrouwen.

Het profiel kent een driedeling:

1. De aanduiding van de competentie, bijvoorbeeld praktische vaardigheid.

2. De omschrijving van de competentie.

3. Het ontwikkelingsniveau. Dit geeft de mate aan waarin een competentie is ontwikkeld, afgaande op het concrete gedrag dat men vertoont. Er zijn drie ontwikkelingsniveau's gedefinieerd:

- Operationeel niveau: beheersing van de competentie in termen van de concrete uitvoering van reguliere werkzaamheden die tot het takenpakket behoren. 
- Tactisch niveau: beheersing van de competentie in zodanige mate dat men de reguliere werkzaamheden overstijgt en bijdraagt aan de verbetering, versterking of ontwikkeling van het eigen functioneren, de eigen vakbekwaamheid en aan de procedurele, organisatorische gang van zaken in de kliniek.

- Strategisch niveau: beheersing van de competentie in zodanige mate dat men beleidsmatig en/of grensverleggend bijdraagt aan de ontwikkeling van het vak, zowel binnen als buiten de kliniek, zowel vakinhoudelijk, organisatorisch, managerial, interdisciplinair als politiek-maatschappelijk.

Tabel 1 geeft een uitgewerkte beschrijving weer van de competentie 'praktische vaardigheid'.

Elk van de 9 competenties is volgens het voorbeeld van tabel 1 uitgewerkt. Voor de definities van de 9 competenties wordt verwezen naar bijlage 1 . In de negen competenties is geen rangorde aangebracht naar belang of gewicht in de selectie.

\section{Toepassing van het competentie- profiel in de selectieprocedure}

In de verschillende fasen van de selectieprocedure geeft het competentieprofiel focus aan het proces van informatieverzamelen en oordeelsvorming. Het sollicitatieformulier nodigt kandidaten uit om per competentie relevante informatie te verschaffen.

De kandidaten krijgen tevens de mogelijkheid referenties te geven. Hiertoe is een speciaal referentieformulier ontwikkeld dat door de referent (meestal een opleider in één van de medische specialisaties) dient te worden ingevuld. Ook dit referentieformulier bevat competentie- gerichte vragen, zoals de vraag naar de competentie 'plannen en organiseren'. Het voordeel van deze competentiegerichte benadering is dat de kandidaat en de referent hun informatie gestructureerd aanleveren. Hierdoor ontstaat een betere vergelijkbaarheid tussen kandidaten en het voorkomt dat relevante informatie onbedoeld niet in beeld komt.

De competenties spelen eveneens in het panelgesprek. Allereerst bevorderen de competenties een efficiënte werkverdeling tussen de beide interviewende panelleden, doordat zij van te voren afspreken wie welke competenties aan de orde stelt en toetst in het interview. Daarnaast zijn de panelleden getraind in het stellen van competentiegerichte vragen. De panelleden beoordelen elke kandidaat eerst onafhankelijk op elke competentie en daarna pas op de algemene geschiktheid voor dit specialisme. Alle beoordelingen worden tevens uitgedrukt in een score op een schaal van 1 (niet geschikt of zeer zwak) tot 5 (uitermate geschikt of zeer goed). Tabel 2 geeft enkele voorbeelden van deze competentiegerichte vragen.

Voorafgaand aan de paneldag krijgen de panelleden een praktijkgerichte training in het competentiegericht interviewen en beoordelen. Deze training voorziet de panelleden niet alleen van concreet instrumentarium in de vorm van technieken en handvatten bij het interviewen en beoordelen, maar maakt hen ook meer bewust van valkuilen in het selectiegesprek zoals het afgaan op de eerste indruk, zelf als panellid te lang aan het woord zijn, niet doorvragen en of er een examen van maken door uitsluitend met kennisvragen te komen.

In de afgelopen drie jaren kreeg steeds een ruime meerderheid van de kandidaten de kans te solliciteren in de opleidingsclusters, zoals tabel 3 laat zien. 
Tabel 1. Uitwerking van de competentie 'praktische vaardigheid'.

\begin{tabular}{ll}
\hline Competentie & Praktische vaardigheid \\
\hline Definitie & $\begin{array}{l}\text { Beschikt over een trefzekere motoriek en efficiënte oog-hand coördinatie; past } \\
\text { operatieve, invasieve en endoscopische technieken soepel en vaardig toe. Werkt } \\
\text { zorgvuldig en efficiënt met apparatuur. Toont ruimtelijk inzicht. }\end{array}$ \\
$\begin{array}{l}\text { Ontwikkelingsniveau } \\
\text { operationeel }\end{array}$ & $\begin{array}{l}\text { Bij selectie: } \\
\text { Toont technische affiniteit: apparaten, instrumenten; toont ruimtelijk en anato- } \\
\text { misch inzicht; heeft een trefzekere fijne motoriek, bijvoorbeeld bij hechtingen, in- } \\
\text { cisies; heeft plezier in het operatief (manueel, instrumenteel) handelen. } \\
\text { In de opleiding: } \\
\text { Beheerst de standaard operatieve technieken; kent alle functies van apparatuur } \\
\text { en instrumenten en weet die te benutten. }\end{array}$ \\
$\begin{array}{l}\text { Ontwikkelingsniveau } \\
\text { tactisch }\end{array}$ & $\begin{array}{l}\text { Ontwikkelt actief de eigen praktische vaardigheid en die van anderen; } \\
\text { draagt bij aan de ontwikkeling en verbetering van de technisch-instrumentele } \\
\text { kanten van de urologie. }\end{array}$ \\
$\begin{array}{l}\text { Ontwikkelingsniveau } \\
\text { strategisch }\end{array}$ & $\begin{array}{l}\text { Zet 'standards of performance' en formuleert kwaliteitseisen met betrekking } \\
\text { tot de operatieve en technische aspecten van dit vak; introduceert geheel } \\
\text { nieuwe operatieve technieken. }\end{array}$ \\
\hline
\end{tabular}

Tabel 2. Voorbeelden van competentiegerichte vragen in de selectieprocedure.

\begin{tabular}{l} 
Setting en onderwerp \\
\hline Vraag in het sollicitatie- \\
formulier naar de competentie \\
'werken in teamverband'
\end{tabular}

Vraag

Geef alstublieft een voorbeeld van een situatie waarin $u$ (intensief) met anderen hebt samengewerkt. Licht toe welke problemen $u$ daarbij ontmoette, wat $u$ daar van vond, hoe $u$ die oploste en wat $u$ achteraf eventueel toch anders zou hebben gedaan. Houdt bij uw beschrijving de volgende aanwijzingen voor ogen:

- Beschrijf de situatie en uw rol daarin op een feitelijke manier.

- Specificeer uw bijdrage en het resultaat daarvan.

- Wees kernachtig; dus geen uitgebreide beschouwing en geen onnodige details.

- Wees erop voorbereid dat $u$, indien u voor het panel komt, diepergaande vragen over uw voorbeeld kunt verwachten.

\section{Vraag een referent naar de competentie 'plannen en organiseren'}

Vraag in het interview naar de competentie 'interpersoonlijke sensitiviteit'
Wat kunt u opmerken over het vermogen van de kandidaat om overzicht over het werk te houden en tijd en werkzaamheden efficiënt in te delen. Zijn hiervan voorbeelden te geven?

Hoe gaat $u$ om met emotionele reacties van anderen? Kunt $u$ daarvan een voorbeeld geven? 
Tabel 3. Verloop selectieprocedure 2000, 2001 en 2002.

\begin{tabular}{cccc}
\hline & Panelinterview & $\begin{array}{c}\text { Sollicitatieronde in } \\
\text { de opleidingsclusters }\end{array}$ & $\begin{array}{c}\text { Geselecteerd voor } \\
\text { de opleiding urologie }\end{array}$ \\
\hline 2000 & 26 & 22 & 17 \\
2001 & 29 & 22 & 14 \\
2002 & 33 & $26+2$ herkansers uit vorig jaar & 21 \\
\hline
\end{tabular}

\section{Evaluatie}

Uit de jaarlijks gehouden, schriftelijke enquête onder kandidaten blijkt dat men in overgrote meerderheid positief is over de gekozen procedure, met name in fase 1 en 2. Als positief worden genoemd aspecten als: de duidelijkheid en beschikbaarheid van informatie, de serieuze en relevante manier van interviewen tijdens het panelgesprek, de mogelijkheid van herkansing en de scherpe vragen in het sollicitatieformulier, die kandidaten aan het denken zetten over hun motivatie voor deze richting. Over de sollicitatieronde in de opleidingsclusters is men kritischer. De gang van zaken daar wordt soms als nogal rommelig ervaren, bijvoorbeeld doordat afspraken voor sollicitatiegesprekken moeilijk kunnen worden gemaakt of doordat er als gevolg van het 'open markt'-principe in deze fase concurrentie tussen opleidingsclusters wordt ervaren. Tot nu toe zijn er nauwelijks klachten gekomen van kandidaten en de enkele klacht die er was kon steeds in goed overleg tussen kandidaat en klachtencommissie worden opgelost. Ook de opleiders zijn, zoals uit een schriftelijke evaluatie blijkt, in hoofdzaak positief over de gekozen procedure en over de kwaliteit van het aanbod aan kandidaten. Uitval uit de opleiding is gering. Volgens een ruwe schatting valt jaarlijks ongeveer 9\% af om uiteenlopende redenen (onder andere: overstap naar een ander specialisme, vertrek naar het buitenland). Bij een minderheid gaat het om dysfunctioneren op vakinhoudelijk gebied en vooral op communicatief en samenwerkingsgebied. Helaas zijn er geen gegevens over het uitvalpercentage vóórdat met deze gestructureerde opzet werd begonnen.

\section{Conclusie en discussie}

Op grond van de ervaringen tot nu toe, inclusief de evaluatie onder kandidaten en opleiders, lijkt de conclusie gerechtvaardigd dat de competentiegerichte benadering bijdraagt aan een transparante en zorgvuldige selectie van kandidaten. Met het opgestelde competentieprofiel beschikt de urologie in Nederland over een gemeenschappelijk en onderbouwd uitgangspunt voor de selectie van assistenten in opleiding.

Een kritisch punt in de gekozen selectieprocedure vormt het spanningsveld tussen de strakke regie en de gewenste vrijheid van opleidingsclusters en individuele opleiders om kandidaten te kiezen. Om aan de wensen van de opleidingsclusters tegemoet te komen is daarom fase 3 aan de procedure toegevoegd. Door de grondige voorselectie hebben opleidingsclusters in elk geval de keuze uit goed gekwalificeerde kandidaten.

Een tweede kritisch punt betreft de verhouding tussen kosten en baten van de procedure. Bij een overaanbod aan kandidaten in combinatie met een beperkt aantal opleidingsplaatsen kan er scherp worden geselecteerd. De laatste jaren is de verhouding tussen aanbod en aantal opleidingsplaatsen verkleind. Dit gegeven verkleint de toegevoegde waarde van een selectieprocedure, 
omdat er gewoonweg weinig te selecteren valt. Aan de andere kant speelt de vraag in hoeverre men bereid is concessies te doen aan de kwaliteit van de instroom en in hoeverre keuzes in deze te rechtvaardigen en eventueel in de opleiding te compenseren zijn. De laatste jaren is bij deze selectieprocedure het accent meer komen te liggen op het weren van ongeschikten dan op het selecteren van de 'besten'.

De ervaringen in de praktijk met het competentieprofiel zijn tot nu toe positief. Niettemin passen ook hier enkele kritische kanttekeningen. De geselecteerde competenties zijn niet uitputtend. Het profiel heeft niet de pretentie dat er geen andere competenties van belang kunnen zijn. De gekozen competenties zijn evenmin definitief wat hun omschrijving en specificering naar ontwikkelingsniveau betreft. Vak en werkveld blijven zich ontwikkelen. Daarnaast is het zinvol het opgestelde profiel te vergelijken met het in Nederland recent ontwikkelde profiel van algemene competenties van de medisch specialist. ${ }^{8}$ Zeker wanneer het competentieprofiel van toekomstig uroloog een rol gaat spelen in de opleiding - op dit moment is dit nog niet het geval - dan dienen de gedragsbeschrijvingen, die zijn gekoppeld aan de competenties, tevens te verwijzen naar de voor de opleiding tot uroloog en medisch specialist geformuleerde eindtermen. Een competentieprofiel blijft echter ook dan geen absoluut en definitief gegeven. Regelmatig dient het profiel op geldigheid en bruikbaarheid te worden bekeken. Tenslotte past de kanttekening dat het onderzoek naar de predictieve validiteit van het profiel nog lopende is. Dit onderzoek richt zich zowel op het verband tussen het algemene oordeel over de geschiktheid en het latere algemene oordeel over het functioneren in de praktijk, als op het verband tussen de afzonderlijke oordelen op de verschillende competenties en de latere prestaties op die verschillende competentiedomeinen tijdens de opleiding. Het onderzoek wordt bemoeilijkt doordat de kwaliteitsverschillen tussen de geselecteerde kandidaten sowieso gering zijn door de strenge voorselectie. $\mathrm{Er}$ is met andere woorden sprake van een sterke 'restriction of range'. Daarnaast laten zich significante samenhangen tussen competentiebeoordelingen in de selectiefase en in de opleiding beter vaststellen wanneer het competentieprofiel ook in de opleiding wordt gehanteerd. Het systematisch verzamelen van competentiebeoordelingen tijdens de opleiding is dan beter mogelijk.

Te overwegen is om de competentiegerichte benadering ook in de opleiding door te voeren. Met een competentieprofiel beschikt men namelijk over een duidelijke meetlat voor een systematische beoordeling van assistenten in opleiding. Daarnaast vormt een competentieprofiel een waardevol uitgangspunt voor het opstellen van een persoonlijk ontwikkelings- of opleidingsplan (POP), zoals in toenemende mate in organisaties het geval is. Competenties helpen niet alleen het beoordelingsproces te onderbouwen, maar geven tevens richting aan persoonlijke en professionele ontwikkeling in het licht van de opleidingseisen. Tenslotte is het dan beter mogelijk onderzoek te doen naar de validiteit van het opgestelde profiel.

Hoe een selectieprocedure wordt ingericht hangt van veel factoren af, zoals de verhouding tussen vraag (het aantal opleidingsplaatsen) en aanbod (het aantal geïnteresseerde kandidaten). De hier gepresenteerde opzet is zeker niet definitief en hoeft dat ook niet te zijn. Het is een goede zaak een selectieprocedure regelmatig kritisch tegen het licht te houden en verantwoorde experimenten met nieuwe elemen- 
ten - zoals fase 3 in de hier gepresenteerde opzet - niet uit de weg te gaan. De aspecten transparantie en zorgvuldigheid dienen bij het inrichten en herinrichten van een selectieprocedure naast de aspecten efficiëntie en voorspellende waarde steeds de leidende beginsels te zijn.

\section{Dankbetuiging}

De auteur dankt twee anonieme reviewers voor hun commentaar op een eerdere versie van dit artikel.

\section{Literatuur}

1. Nederlandse Vereniging voor Personeelsmanagement en Organisatieontwikkeling. NVP-sollicitatiecode. Nieuwegein; september 2003.

2. Loo RPJM van de, Schroeder JJM. Keuzeprocedure assistenten urologie 2001, gang van zaken en aandachtspunten. De Urograaf 2001;12(6):11-4.

3. Fine PL, Hayward RA. Do the criteria of resident selection committees predict residents' performances? Acad Med 1995;70(9):834-8.

4. Taylor CW, Albo D. Measuring and predicting the performances of practicing physicians: an overview of two decades of research at the University of Utah. Acad Med 1993;68(2):S65-7.

5. Drenth PJD. De waarde van het selectie-interview. Gedrag en Organisatie 1990;1(2):18-25.

6. Bie D de. Competenties, wat zijn dat en wat doen we ermee? Tijdschrift voor Medisch Onderwijs 2002;21(4):161-6.
7. Hoekstra HA, Sluis E van. Management van competenties, het realiseren van HRM. Assen: Van Gorcum; 1999.

8. KNMG. Algemene competenties van de medisch specialist. Bijlage 1 bij het Kaderbesluit CCMS, als bedoeld in artikel B.11, eerste lid, onder e. KNMG; oktober 2003.

9. Loo RPJM van de. Competentieprofiel Toekomstig Uroloog. Rapport uitgebracht aan de Toelatingscommissie Urologie. Utrecht: Quamens; februari 2000.

10. SHL-competentieset. Intern rapport SHL-group. Utrecht; 2000.

11. Schipholt IL. De basis van de zorg is in elk land hetzelfde. Het Canadees opleidingsmodel voor medisch specialisten toegelicht door Frank Jason. Med Contact 2003;58(22):891-4.

12. Metz JCM, Verbeek-Weel AMM, Huisjes HJ. Raamplan 2001 Artsopleiding; bijgestelde eindtermen van de artsopleiding. Nijmegen: Mediagroep; 2001.

13. Crul BVM. Het leren vernieuwd. Chris Plasmans en Otto Bleker (CCMS) over de opleiding tot medisch specialist. Med Contact 2003;58(1):11-4.

De auteur:

Dr. R.P.J.M. van de Loo is psycholoog en mededirecteur van adviesbureau Quamens te Bussum. Hij heeft de afgelopen jaren de selectieprocedure van toekomstig assistenten urologie begeleid in nauwe samenwerking met de Toelatingscommissie Urologie.

\section{Correspondentieadres:}

Dr. R.P.J.M. van de Loo, Stationsplein 5, 1404 AM

Bussum,quamens@quamens.nl,www.quamens.nl.

\section{Summary}

A clear procedure, an approach based on a well-defined competency profile as well as clearly established responsibilities with respect to organisation, execution and quality control are the components that characterise the procedure for the selection of candidates for specialty training in urology in The Netherlands. The procedure consists of three stages: a written pre-selection phase based on application letters, an interview with a panel of urologists and the actual application phase at one of the six training 'clusters'. The procedure and the competency profile are discussed in the light of three essential criteria: thoroughness, transparency and validity. Attention is paid to the importance of the critical monitoring of the procedure and continuous evaluation of its predictive validity. Potential implications of the current developments with regard to the final objectives and general competencies of the specialty training programmes in The Netherlands are discussed. (Van de Loo RPJM. Competency-based selection of future urologists: experience from practice. Dutch Journal of Medical Education 2004;23(1):30-39.) 
Bijlage 1. Competentieprofiel 'Toekomstig Uroloog': omschrijvingen van de competenties.

\begin{tabular}{|c|c|}
\hline Vakgerichtheid & $\begin{array}{l}\text { Gedrevenheid zich te ontwikkelen in het vak, zowel praktisch, klinisch } \\
\text { als wetenschappelijk. Neemt actief deel aan onderzoeksprojecten; geeft } \\
\text { voordrachten en publiceert; reflecteert kritisch op het eigen handelen als } \\
\text { specialist. Staat open voor nieuwe ontwikkelingen. }\end{array}$ \\
\hline Werken in teamverband & $\begin{array}{l}\text { Werkt met anderen (collega's, verpleging, opleiders) samen om team- } \\
\text { doelen te bereiken, ondersteunt anderen. Zoekt de samenwerking en } \\
\text { deelt informatie met anderen. Staat open voor feedback en constructieve } \\
\text { kritiek. }\end{array}$ \\
\hline Integer handelen & $\begin{array}{l}\text { Komt afspraken na; houdt zich aan de beroepsethiek; stelt het belang van } \\
\text { de patiënt, het team, et cetera boven het eigen belang. Houdt woord. } \\
\text { Toont integriteit en eerlijkheid in het contact met anderen. }\end{array}$ \\
\hline Oordeelsvorming & $\begin{array}{l}\text { Neemt rationele, realistische en gegronde beslissingen, gebaseerd op het } \\
\text { overwegen en helder analyseren van alle beschikbare feiten en alternatie- } \\
\text { ven. }\end{array}$ \\
\hline Praktische vaardigheid & $\begin{array}{l}\text { Beschikt over een trefzekere motoriek en efficiënte oog-hand coördinatie; } \\
\text { past niet-invasieve, operatieve en endoscopische technieken soepel en } \\
\text { vaardig toe. Werkt zorgvuldig en efficiënt met apparatuur. Toont ruimte- } \\
\text { lijk inzicht. }\end{array}$ \\
\hline Plannen en organiseren & $\begin{array}{l}\text { Stelt duidelijke prioriteiten; maakt een planning van de activiteiten om } \\
\text { tijd en middelen optimaal te benutten; houdt toezicht op het halen van } \\
\text { de doelstellingen; komt toe aan alle facetten van het takenpakket van een } \\
\text { uroloog (in opleiding), zoals o.a. administratie en onderzoek. Raakt niet } \\
\text { achterop in het werk. }\end{array}$ \\
\hline Interpersoonlijke sensitiviteit & $\begin{array}{l}\text { Heeft oog, zorg en respect voor de gevoelens van anderen, toont belang- } \\
\text { stelling voor de mening van anderen, stelt zich positief en tolerant op ten } \\
\text { opzichte van verschillen in behoeften en zienswijzen. }\end{array}$ \\
\hline Aandacht voor kwaliteit & $\begin{array}{l}\text { Zet zich in voor het bereiken en behouden van kwaliteit; stelt hoge eisen } \\
\text { aan eigen prestaties en die van anderen. }\end{array}$ \\
\hline Zelfvertrouwen & $\begin{array}{l}\text { Onafhankelijk en zelfstandig; heeft realistisch vertrouwen in het } \\
\text { vermogen de juiste handelwijze te kiezen en in de kans van slagen van } \\
\text { eigen initiatieven; is in staat bij tegen- en/of weerstand het eigen stand- } \\
\text { punt rustig en zelfverzekerd naar voren te brengen. }\end{array}$ \\
\hline
\end{tabular}

